\title{
Contribution of a synchronic teleneurology program to decrease the patient number waiting for a first consultation and their waiting time in Chile
}

Freddy Constanzo ${ }^{1,2^{*}}$ D. Paula Aracena-Sherck ${ }^{3}$, Juan Pablo Hidalgo ${ }^{4}$, Lorena Peña ${ }^{1,2}$, Mery Marrugo ${ }^{1,2}$, Jonathan Gonzalez ${ }^{1,2}$, Gerardo Vergara ${ }^{5}$ and Cristóbal Alvarado 3,6

\section{Abstract: Backround}

There is a shortage of medical specialists in Chile, including neurologists; currently, there are 56,614 patients waiting for a first adult Neurology appointment in the country. The Teleneurology Program at the Hospital Las Higueras de Talcahuano (HHT) was implemented in 2015 to help reduce both the number of patients waiting for a first consultation and their waiting times.

Methods: This retrospective study analyzed a cohort of 8269 patients referred to the HHT Neurology clinic between 2013 and 2018, from primary, secondary, and tertiary health centers. Cox regression analyses were performed to determine the factors influencing each outcome (number of patients waiting for a consultation and waiting time), such as age, gender, referral health establishment and the type of consultation (whether in situ at the HHT or by synchronic telepresence through the Teleneurology Program).

Results: Out of the 8269 patients included in the study, 1743 consulted the neurologist through the Teleneurology Program, while 6526 received a consultation in situ at the HHT. Since its implementation (2015) until the end of 2018, the Teleneurology program contributed to decrease the number of patients waiting for their first appointment from 3084 to 298. Waiting time for the first consultation was $60 \%$ shorter for patients enrolled in the Teleneurology program than those with consultation in situ at HHT ( $6.23 \pm 6.82$ and $10.47 \pm 8.70$ months, respectively). Similar differences were observed when sorting patient data according to the referral health center. Cox regression analysis showed that patients waiting for a traditional in situ first adult Neurology consultation at the HHT had a higher risk (OR $=6.74)$ of waiting 90\% longer than patients enrolled in the Teleneurology Program, without significant differences due to gender or age.

Conclusions: Data from this study show a significant contribution of the Teleneurology Program at the HHT to decrease the number of patients waiting for a first consultation with a neurologist, as well as shorter waiting times, when derived from primary and secondary health centers.

Keywords: Telemedicine, Teleneurology, Adult neurology

\footnotetext{
* Correspondence: teleneurologiahht@gmail.com

${ }^{1}$ Neurology Unit, Hospital Las Higueras, Alto Horno 777, Talcahuano, Chile

${ }^{2}$ Medical Program in Adult Neurology, School of Medicine, Universidad

Católica de la Santísima Concepción, Concepción, Chile

Full list of author information is available at the end of the article
}

(c) The Author(s). 2020 Open Access This article is distributed under the terms of the Creative Commons Attribution 4.0 International License (http://creativecommons.org/licenses/by/4.0/) which permits unrestricted use, distribution, and reproduction in any medium, provided you give appropriate credit to the original author(s) and the source, provide a link to the Creative Commons license, and indicate if changes were made. The Creative Commons Public Domain Dedication waiver (http://creativecommons.org/publicdomain/zero/1.0/) applies to the data made available in this article, unless otherwise stated. 


\section{Contributions to the literature}

Since 2015, the Teleneurology Program at Hospital Las Higueras de Talcahuano has admitted adult Neurology patients. To evaluate the impact of Teleneurology on the population, we designed a retrospective study of 8269 patients from the hospital's Neurology clinic. This article is the first to report a significant contribution of the Teleneurology Program to the decrease in the number and time of adult neurology patients waiting for a first appointment, when derived from primary and secondary health centers. Research and data collection approved by the Ethics Committee of the Talcahuano Health Service (attached in Spanish).

\section{Background}

Chile is a South American country with 19,107,216 inhabitants as of 2019 [1], and a very particular continental geography of about 2650 miles $(4270 \mathrm{~km})$ in length, only 110 miles $(175 \mathrm{~km})$ in average width, and with the Pacific Ocean and the Andes Mountains naturally isolating its territory from the rest of the world. These characteristics that make the country a perfect touristic destination also hinder public transportation outside of its capital, Santiago. Taken together with a shortage of medical specialists, most of the tertiary health care is concentrated in Santiago and within the private health systems [1, 2]. As of December 2016, only $50 \%$ of adult neurologists in the country were affiliated to Public Health System [3], which provides healthcare to approximately $80 \%$ of the total population [4]. Thus, with 56,614 patients waiting for their first appointment as of June 30, 2019, Neurology ranks number 7 among the Chilean medical specialties with patients waiting for their first appointment [5].

Telemedicine implementation and development within the Chilean Public Health System arises as an opportunity to overcome both specialist shortage and transportation issues [6]. In the country, there are reported successes in the use of telemedicine for decreasing the number of patients waiting for a first consultation in Ophthalmology [7], Cardiology [8], Dermatology [9], and Orthopedics [10]. In contrast, no data has been reported for Teleneurology, as it appears to be only rarely implemented in some Chilean Public Health establishments [11, 12].

The Talcahuano Health Service (SST), located about 300 miles $(500 \mathrm{~km})$ south of Santiago, provides healthcare to 360,565 inhabitants of the region in 2019 [13]. The SST manages three hospitals, a Neurology Unit (NU) and a Telemedicine program (Teleprocess Unit), located at the Hospital Las Higueras de Talcahuano (HHT). The HHT Teleprocess Unit was created in 2008 as an asynchronous system, allowing storage and transfer of images, and consequently, remote clinical decision making. Since then, this Telemedicine program has allowed several landmarks: i) improvement in the prioritization of care for users with greater health risk, ii) improvement in the patient clinical registry, iii) efficient integration between the diverse professionals and technicians within a health team, and iv) contribution to the continuity in the follow-up and management of chronic patients [14].

The Teleneurology Program was created at the HHT Neurology Unit in March 2015 to help manage the 3084 adult neurological patients waiting for a first consultation. This program operates in synchronous mode, in which patients consult with a general practitioner trained for this purpose at their local health care establishment, in the telepresence of the neurologist specialist through an HDTV videoconference system [15]. This type of system has allowed the remote care of patients derived from primary and secondary local healthcare facilities $[16,17]$ as well as improved the flow of consultations of adult neurological patients, with very high user satisfaction $[3,15]$.

Despite, the positive experiences that have previously been reported, regarding significant improvements in the efficiency of patient care by telemedicine programs in other regions $[10,18,19]$, evidence in Chilean teleneurology programs remain unpublished. Moreover, since the implementation of the Teleneurology Program, a seemingly decreasing trend of the number of patients waiting for their first consultation appears to be in contrast with the increasing trend in this figure for the rest of the country. Therefore, we set out to investigate the impact of the HHT Teleneurology Program on two main outcomes: the number of patients waiting for an adult neurology consultation and their waiting times. The present study is the first report of the effect of such a program improving both outcomes in Chile.

\section{Methods}

\section{Description of the study population}

For this retrospective cohort study, we analyzed data from patients referred to the HHT Neurology clinic, between January 2013 and December 2018, whether consulting in situ at the HHT or enrolled in the Teleneurology Program. Patients were referred from the following primary health facilities of the Public Health System: i) Community Family Health Centers (CECOFS for the Spanish acronym) 8 de Mayo, Cerro Estanque, Cosmito, El Santo, Esmeralda, España, Forjadores, Govinden, Libertad Gaete, Llafkelén, Los Lobos, Parque Central, Punta Parra, Rene Schneider, and Ríos de Chile, and ii) Family Health Centers (CESFAM for the Spanish acronym) Alberto Reyes, Bellavista, Hualpencillo, La Floresta, Leocan Portus, Lirquén, Los Cerros, Paulina Avendaño, Penco, San Vicente, Talcahuano Sur, and Posta Dichato. Patients were also referred by a secondary health center (Mental Health Center, COSAM for the Spanish acronym) Hualpén and the tertiary health 
centers: HHT, Tomé Hospital, Penco-Lirquén Hospital, with the latter ending its participation in the program in 2018 (Additional file 1). Details of the modality of synchronous care of the Teleneurology consultation and the inclusion and exclusion criteria of the patients included in this study were previously described by Constanzo et al. [15].

\section{Variables}

Main outcomes analyzed were:

i) Number of patients waiting for their first consultation, defined as the first care appointment of the patient with his or her medical practitioner, namely a neurologist in the present study, and.

ii) Waiting time for the first consultation (WT as acronym in Results section and tables), which refers to the time that elapses between the date when the patient requests an appointment and the date when the appointment takes place, measured in months. Follow-up and subsequent appointments are not included in the present study.

Independent variables analyzed were: $i)$ age $(60<$, and $>=60$ ), ii) gender (male or female), iii) referral healthcare facility (primary, secondary, or tertiary), and iv) type of appointment (in situ at HHT or by telepresence through the Teleneurology Program). Finally, patients unnecessarily referrals come from patients referred to general practitioner for face-to-face attention in the HHT. These patients are registered in the system as poorly derived.

\section{Neurology medical team}

The HHT Neurology Unit consists of 11 neurologists and two general practitioners. The neurologist group dedicate, as a group, $74 \mathrm{~h}$ per week to consultation in situ at HHT and $17 \mathrm{~h}$ per week to the Teleneurology Program. The general practitioners dedicate, as a group, $21 \mathrm{~h}$ per week for: $i$ ) coordination of care and follow-up of patients waiting for an appointment, ii) extension of chronic patient prescriptions, iii) follow-up of patients with a prolonged medical license or in the process of requesting disability pension. This allows the team of neurologists to focus exclusively on the resolution of patients' neurological problems.

\section{Statistical analysis}

The descriptive characteristics of the patients are shown as mean \pm standard deviation and frequency (percentage), for continuous and categorical variables, respectively. A Kaplan-Meier test was carried out to evaluate the behavior of the WT outcome. Variables that could influence the WT outcome were analyzed through a
Cox regression analysis. Results are presented as Odds Ratio (OR), and estimated coefficients (beta coefficients). Significance was set at $p<0.05$. All analyses were performed with SPSS, version 25.

\section{Results}

\section{Patient cohort description}

This study analyzed retrospectively a cohort of 8269 adult outpatients who obtained their first appointment with a neurologist at the Neurology clinic of the Hospital Las Higueras de Talcahuano (HHT), between January 2013 and December 2018. Out of the total, 6526 patients $(79 \%)$ consulted the specialist in situ at HHT and 1743 (21\%) had their appointment with the telepresence of the neurologist, through the Teleneurology Program at HHT. As summarized, 2829 patients (34\%) were male, while $5440(66 \%)$ were female (Table 1). similar gender distribution percentages resulted after sorting patients in terms of the type of appointment (in situ or by telepresence).

On the other hand, 1382 (17\%) patients were between 15 and 30 years of age, 946 (11\%) were between 31 and 45 years old, $1823(22 \%)$ were 46 and 60 years of age, and 4118 (50\%) were over 60 years old. Similar age distribution was observed when grouping patients according to their type of appointment.

Finally, In situ neurologist attention at the HHT referred 3411 (52\%) patients from primary health facilities, $42(1 \%)$ from secondary health services, and $3073(47 \%)$ from tertiary health care centers. The Teleneurology Program referred 1591 patients (91\%) were from primary centers, and 152 (9\%) from tertiary facilities, with no patients being referred from secondary services (Table 1).

\section{Number of patients waiting for their first neurology appointment}

The Neurology clinic at HHT began the follow up of patients waiting for a first appointment with a specialist in March 2015. Table 2 shows the time course of the number of patients in this "waiting list" (for the Spanish legal term "lista de espera") from March 2015 until December 2018. Out of the total 3084 patients waiting by March 2015, 743 (24\%) were since 2013, 1740 (56\%) since 2014, and 611 (20\%) since the beginning of 2015. By December 2018, only 298 patients ( $90 \%$ lower than those in March 2015) were waiting for their appointment: 68 (23\%) waiting since 2017 and 230 (80\%) from 2018 (Table 2). Unfortunately, the patients from 2017 could be reached by the health service. Interestingly in certain cases, patients were unnecessarily referred to the Neurology clinic, due to misclassification of the symptoms. The clinic registry of declares declines from 105 patients referred under this situation in 2015, 82 in 2016, 29 in 2017, to 7 in 2018. 
Table 1 General descriptives of the patients treated by the HHT Neurology clinic, either in situ or through the Teleneurology program, Jan 2013 to Dec 2018

\begin{tabular}{|c|c|c|c|c|c|c|}
\hline & \multicolumn{2}{|c|}{$\begin{array}{l}\text { Total Cohort } \\
(n=8269)\end{array}$} & \multicolumn{2}{|c|}{$\begin{array}{l}\text { Appointment in situat the HHT } \\
(n=6526)\end{array}$} & \multicolumn{2}{|c|}{$\begin{array}{l}\text { Appointment through the Teleneurology Program } \\
(n=1753)\end{array}$} \\
\hline & $n$ & $\%$ & $n$ & $\%$ & $n$ & $\%$ \\
\hline \multicolumn{7}{|l|}{ Gender } \\
\hline Male & 2829 & 34 & 2265 & 35 & 564 & 32 \\
\hline Female & 5440 & 66 & 4261 & 65 & 1179 & 67 \\
\hline \multicolumn{7}{|c|}{ Age group (years of age) } \\
\hline $15-30$ & 1382 & 17 & 1164 & 18 & 218 & 13 \\
\hline $31-45$ & 946 & 11 & 705 & 10 & 241 & 14 \\
\hline $46-60$ & 1823 & 22 & 1422 & 22 & 401 & 23 \\
\hline Over 60 & 4118 & 50 & 3235 & 50 & 883 & 50 \\
\hline \multicolumn{7}{|c|}{ Referral healthcare facility } \\
\hline Primary & 5002 & 60 & 3411 & 52 & 1591 & 91 \\
\hline Secondary & 42 & 1 & 42 & 1 & 0 & 0 \\
\hline Tertiary & 3225 & 39 & 3073 & 47 & 152 & 9 \\
\hline
\end{tabular}

\section{Waiting time for the first neurology appointment}

To evaluate the possible effect that telemedicine may might had on the patient's waiting time (WT) for their first Neurology appointment at the Neurology clinic of the HHT, WT data was distributed in 4 frames: up to 6 months, 7 to 10 months, 13 to 24 months, and over 24 months (Table 3 ). The average WT was $10.5 \pm 8.7$ months for patients consulting in situ at the HHT and $6.23 \pm 6.82$ months. Out of the total cohort analyzed in this study, 3845 patients $(47 \%)$ waited for up to 6 months for their appointment, 944 (11\%) waited between 7 and 12 months, 2618 (32\%) waited between 13 and 24 months, and $862(10 \%)$ waited for over 24 months, a distribution similar to that observed in the group of patients that consulted their neurologist in situ at the HHT (Table 3). In contrast, patients enrolled in the Teleneurology Program showed a different distribution, with 1053 (60\%) waiting for up to 6 months, 228 (13\%) waiting between 7 and 12 years, 346 (20\%) waiting between 13 and 24 months, and 116 (7\%) waiting for over 24 months (Table 3 ).

Kaplan-Meier survival analyses to better understand the putative effect of the Teleneurology program on patient WT, which resulted in the selection of 3 variables significantly showing an effect on the mean WT: male gender, female gender and patient referral from primary and secondary healthcare facilities (mean and median data summarized in Table 4). As depicted in Fig. 1, Kaplan-Meier function graphs show lower WT for patients who were enrolled in the Teleneurology Program compared to those who consulted their specialist in situ at the HHT. Male patients (panel A in Fig. 1) displayed significant difference in the median
WT, with $21.7 \pm 0.18$ months (95\% CI 21.3-22.0) for an in situ appointment, and $16.2 \pm 0.60$ months (95\% CI 15.117.4) for an appointment with the telepresence of the specialist. A significant difference $(p<0.05)$ was also found in the median WT of female patients (panel B in Fig. 1), with $16.9 \pm 0.29$ months (95\% CI 16.3-17.5) for an appointment in situ at HHT, and $7.2 \pm 0.45$ months $(95 \% \mathrm{CI}$ 6.3-8.1) when enrolled in the Teleneurology Program. The third variable which resulted with a significant median WT difference was the referral from primary or secondary healthcare facilities (panel C in Fig. 1), with $18.3 \pm$ 0.15 months (95\% CI 18.6-19.1) for in situ appointments and $4.4 \pm 0.29$ months (95\% CI 3.8-5.0) for telepresence appointments. No differences were found when analyzing data according to any of the age groups or when patients were referred by tertiary healthcare services.

Finally, a backward Cox regression analysis was carried out to understand the effect sizes of the 3 variables identified by the Kaplan-Meier analysis. As shown in Table 5, this analysis resulted in only one variable displaying a significant effect size $(p<0.001)$ on patient WT: "Type of Appointment". This variable showed a beta coefficient of $1.91 \pm 0.29$ fold WT when it took place in situ at the HHT, as compared with patients consulting their neurologist by telepresence. This resulted in an odds ratio of 6.74 in the WT of patients with a traditional in situ appointment, compared to those enrolled in the Teleneurology Program (Table 5).

\section{Discussion}

In Chile, the shortage of medical specialists added to the difficulties in the country's geography give telemedicine an opportunity to improve access of patients to specialized 
Table 2 Number of patients waiting for a first appointment with a neurologist at the Neurology clinic of the HHT

\begin{tabular}{|c|c|c|c|c|c|c|c|}
\hline \multirow[b]{2}{*}{ Report date } & \multicolumn{7}{|c|}{ Number of patients during each calendar year ${ }^{a}$} \\
\hline & 2013 & 2014 & 2015 & 2016 & 2017 & 2018 & $2013-2018$ \\
\hline $01 / 03 / 2015$ & 743 & 1730 & 611 & - & - & - & 3084 \\
\hline $01 / 11 / 2015$ & 9 & 1065 & 1401 & - & - & - & 2475 \\
\hline $01 / 12 / 2015$ & - & 907 & 1260 & - & - & - & 2167 \\
\hline 01/02/2016 & - & 817 & 1205 & 91 & - & - & 2113 \\
\hline 01/04/2016 & - & 711 & 1269 & 347 & - & - & 2327 \\
\hline 01/05/2016 & - & 660 & 1105 & 99 & - & - & 1864 \\
\hline 01/06/2016 & - & 583 & 1084 & 581 & - & - & 2248 \\
\hline 01/09/2016 & - & 506 & 940 & 971 & - & - & 2417 \\
\hline 01/10/2016 & - & 386 & 923 & 1035 & - & - & 2344 \\
\hline $01 / 12 / 2016$ & - & - & 640 & 1144 & - & - & 1784 \\
\hline 01/01/2017 & - & - & 623 & 1490 & 38 & - & 2151 \\
\hline 01/03/2017 & - & - & 530 & 1151 & 225 & - & 1906 \\
\hline 01/06/2017 & - & - & 212 & 864 & 420 & - & 1496 \\
\hline 01/07/2017 & - & - & 188 & 727 & 555 & - & 1470 \\
\hline 01/09/2017 & - & - & 156 & 695 & 627 & - & 1478 \\
\hline 01/11/2017 & - & - & 38 & 675 & 789 & - & 1502 \\
\hline $01 / 12 / 2017$ & - & - & - & 597 & 851 & - & 1448 \\
\hline 01/01/2018 & - & - & - & 541 & 874 & 2 & 1417 \\
\hline 01/02/2018 & - & - & - & 431 & 824 & 112 & 1367 \\
\hline 01/03/2018 & - & - & - & 359 & 756 & 226 & 1341 \\
\hline 01/04/2018 & - & - & - & 319 & 730 & 281 & 1330 \\
\hline 01/05/2018 & - & - & - & 137 & 659 & 366 & 1162 \\
\hline 01/06/2018 & - & - & - & 112 & 499 & 379 & 990 \\
\hline 01/07/2018 & - & - & - & 92 & 236 & 417 & 745 \\
\hline 01/09/2018 & - & - & - & 21 & 154 & 284 & 459 \\
\hline 01/10/2018 & - & - & - & - & 113 & 226 & 339 \\
\hline 01/11/2018 & - & - & - & - & 93 & 225 & 318 \\
\hline $01 / 12 / 2018$ & - & - & - & - & 68 & 230 & 298 \\
\hline
\end{tabular}

${ }^{a}$ Data extracted from official reports from the Ministry of Health of Chile [20] for all patients of the cohort studied. It is of note that a group of patients are counted more than once among consecutive reports, for as long as they continue waiting for their appointment healthcare. Mobility issues are of particular relevance to adult neurology patients due to many of the characteristic clinical manifestations of their illnesses. Telemedicine arises as an opportunity to improve access to specialized neurological care for patients who otherwise would have to their travel to tertiary healthcare facilities, where the specialists work.

By January 2015, the Hospital Las Higueras de Talcahuano (HHT), a tertiary healthcare center of the Chilean Public Health System located in the south of the country, had 3084 patients waiting for a first appointment with an adult neurology specialist, 743 of whom had been waiting since 2013. Thus, the institution created a Teleneurology Program for its Neurology clinic patients in March 2015, to improve their access to the specialist by way of an appointment with a general medical practitioner at their local primary healthcare facility and with the synchronous telepresence of the neurologist, located at HHT. The present study was aimed to evaluate the impact of such a program in both the number of patients waiting for a first appointment with a specialist in adult Neurology and the waiting time for the appointment to take place.

Data from this study show that there was a $90 \%$ decrease in the number of patients waiting for their first appointment with a neurologist between January 2015 and December 2018, which could have been contributed by the Teleneurology Program. Kaplan-Meier survival curves confirmed that patients enrolled in this program had to wait less time for their first appointment, as compared with patients that obtained a traditional in situ appointment, by $25 \%$ for males and $57 \%$ for females in the median waiting time. The difference in the effect between genders is likely to be rooted in cultural differences regarding patient compliance of Chilean females and males, characteristic in developing countries [21]; however, a size effect cannot be discarded due to the gender distribution of the cohort (over 65\% female), which requires further research and it is out of the scope of the present study. On the other hand, the analysis also showed that patients referred to the Teleneurology Program from primary and secondary healthcare facilities had to wait $56 \%$ less time compared to those who had their appointment in situ at HHT. This result supports

Table 3 Patient waiting time for their first appointment at the Neurology clinic of HHT

\begin{tabular}{|c|c|c|c|c|c|c|}
\hline \multirow[t]{2}{*}{$\begin{array}{l}\text { Waiting time } \\
\text { frame (months) }\end{array}$} & \multicolumn{2}{|c|}{$\begin{array}{l}\text { Total Cohort } \\
(n=8269)\end{array}$} & \multicolumn{2}{|c|}{$\begin{array}{l}\text { Appointment in situ at the HHT } \\
(n=6526)\end{array}$} & \multicolumn{2}{|c|}{$\begin{array}{l}\text { Appointment through the Teleneurology Program } \\
(n=1753)\end{array}$} \\
\hline & $n$ & $\%$ & $n$ & $\%$ & $n$ & $\%$ \\
\hline Up to 6 & 3845 & 47 & 2792 & 43 & 1053 & 60 \\
\hline $7-12$ & 944 & 11 & 716 & 11 & 228 & 13 \\
\hline $13-24$ & 2618 & 32 & 2272 & 35 & 346 & 20 \\
\hline Over 24 & 862 & 10 & 746 & 11 & 116 & 7 \\
\hline
\end{tabular}


Table 4 Kaplan-Meier statistics of patients waiting for a first appointment at the Neurology clinic of HHT

\begin{tabular}{|c|c|c|c|c|c|c|c|c|}
\hline \multirow{3}{*}{$\begin{array}{l}\text { Type of } \\
\text { appointment }\end{array}$} & \multicolumn{8}{|c|}{ Waiting time (months) } \\
\hline & \multirow{2}{*}{$\begin{array}{l}\text { Estimated } \\
\text { Mean }\end{array}$} & \multirow[t]{2}{*}{ SE } & \multicolumn{2}{|l|}{$95 \% \mathrm{Cl}$} & \multirow{2}{*}{$\begin{array}{l}\text { Estimated } \\
\text { Median }\end{array}$} & \multirow[t]{2}{*}{ SE } & \multicolumn{2}{|l|}{$95 \% \mathrm{Cl}$} \\
\hline & & & Lower & Upper & & & Lower & Upper \\
\hline \multicolumn{9}{|l|}{ Male gender } \\
\hline In situ & 19.1 & 0.21 & 18.7 & 19.5 & 21.7 & 0.18 & 21.3 & 22.0 \\
\hline Teleneurology & 15.4 & 0.68 & 14.1 & 16.7 & 16.2 & 0.60 & 15.1 & 17.4 \\
\hline \multicolumn{9}{|l|}{ Female gender } \\
\hline In situ & 14.0 & 0.13 & 13.7 & 14.2 & 16.9 & 0.29 & 16.3 & 17.5 \\
\hline Teleneurology & 9.1 & 0.24 & 8.6 & 9.5 & 7.2 & 0.45 & 6.3 & 8.1 \\
\hline \multicolumn{9}{|c|}{ Referral from primary or secondary healthcare facilities } \\
\hline In situ & 15.7 & 0.14 & 15.4 & 16.0 & 18.9 & 0.15 & 18.6 & 19.1 \\
\hline Teleneurology & 6.9 & 0.17 & 6.5 & 7.2 & 4.4 & 0.29 & 3.8 & 5.0 \\
\hline
\end{tabular}

SE Standard error, Cl Coefficient interval

the idea that the program is taking charge of the burden of neurology patients particularly in areas far away from the tertiary healthcare facility where the neurologist is located, which are also the areas with the lower income within the population assigned to the HHT.

Further statistical analysis through Cox regression identified the Teleneurology Program with a significant effect size on patient waiting time for a first appointment with the specialist. In fact, a patient enrolled in the Teleneurology Program at HHT had to wait almost 7fold less time for their appointment to take place. Therefore, the present study is the first to report an improvement of access to a neurology specialist in a tertiary healthcare facility with the use of a telemedicine-based system. It is possible that the success of the Teleneurology Program for patients referred from primary and secondary healthcare facilities is related to the higher feasibility of a neurology patient to travel to a local healthcare center compared to the tertiary service where the specialist work, which is directly related to the mobility issues affecting this population of patients in particular. However, similar results have been reported in Chile with synchronous telemedicine programs in other medical specialties, such as dermatology [22], ophthalmology [23], and orthopedics [10]. Therefore, further research is required to identify whether the travel distance of patients to the tertiary healthcare facility (Fig. 2) is a risk factor in the waiting time for a first appointment.

Taken together, results from this study support the idea that this type of telemedicine-based system can function as a screening and triage tool, contributing to solve the burden of out-patient neurological disease. In fact, the number of patients mistakenly referred to the Neurology clinic at HHT decreased 93\% since the creation of the Teleneurology Program, supporting this idea. Recent studies in telehealth have described that one of the advantages of this health management system, in its ability to cover large areas of territory by improving accessibility $[24,25]$ and as has been shown in

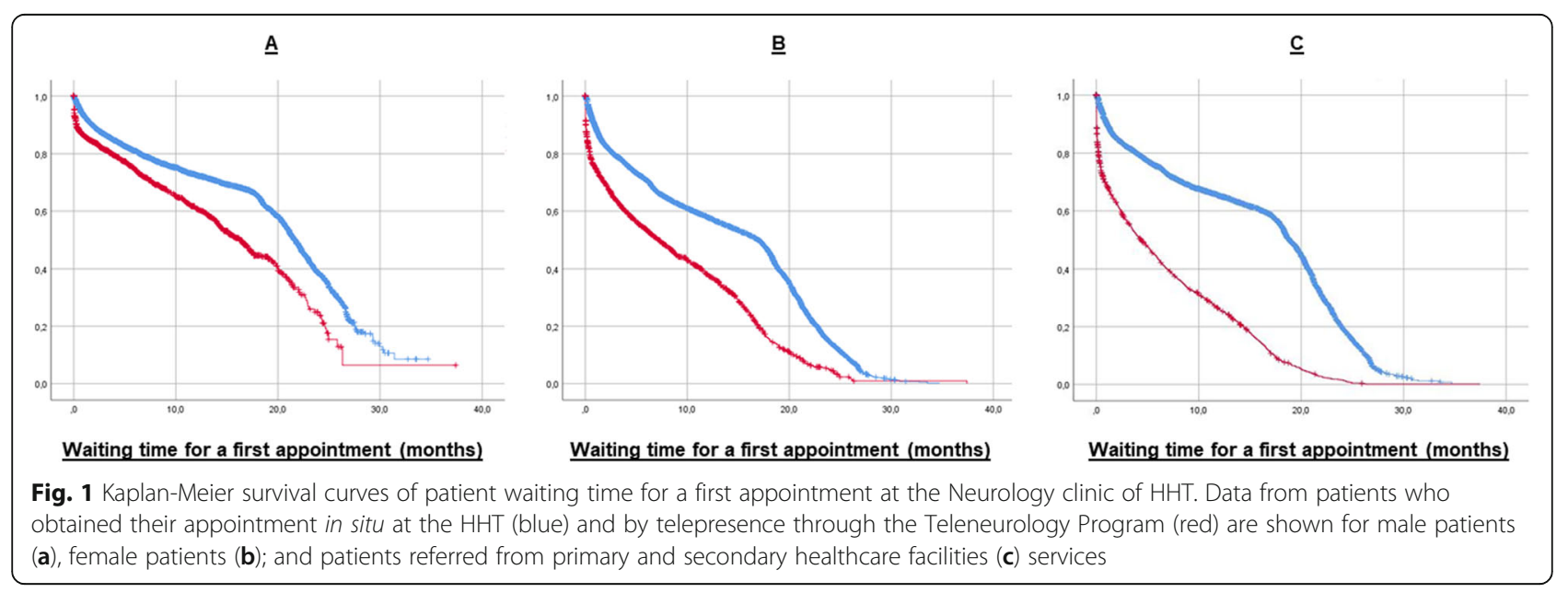


Table 5 Cox regression statistics of patients waiting for a first appointment at the Neurology clinic OF HHT

\begin{tabular}{llllllll}
\hline Step & Variable & Beta & SE & Wald & df & $P$ & OR \\
\hline 1 & Gender & -0.03 & 0.05 & 0.44 & 1.00 & 0.51 & 0.97 \\
& Type of Appointment & 1.91 & 0.08 & 504.84 & 1.00 & $<0.001$ & 6.75 \\
& Age over 60 years old & 0.08 & 0.05 & 2.64 & 1.00 & 0.10 & 1.08 \\
2 & Type of Appointment & 1.91 & 0.08 & 504.63 & 1.00 & $<0.001$ & 6.74 \\
& Age over 60 years old & 0.08 & 0.05 & 2.79 & 1.00 & 0.09 & 1.08 \\
\hline
\end{tabular}

Regression analysis was performed with the Backward method

SE Standard error, $d f \mathrm{x}, O R$ Odds ratio

numerous studies, the most serious patients can be identified and referred for an in situ appointment, emergency or admittance as an in-patient $[22,26]$.

Overall, the Teleneurology Program at HHT appeared to contribute to the containment of the overwhelmed demand of in situ appointment, by covering patients of lower complexity according to clear criteria of reference and counter-reference. As in other latitudes, the Teleneurology Program at HHT improved the control and monitoring of neurological patients with clear and stable pathologies [27, 28]. The HHT Teleneurology system contributes significantly to the continuous education of primary health care doctors, neurology residents and neurologist doctors, by teaching them how the Teleneurology system works before beginning their functions in Teleneurology program, as well as, accompanying both professionals in the moment in which that each patient is treated, what is widely supported in the current literature [29-31].

Taking together with the recent report showing a high satisfaction perception by patients with access to this program [15], results from the present work strongly

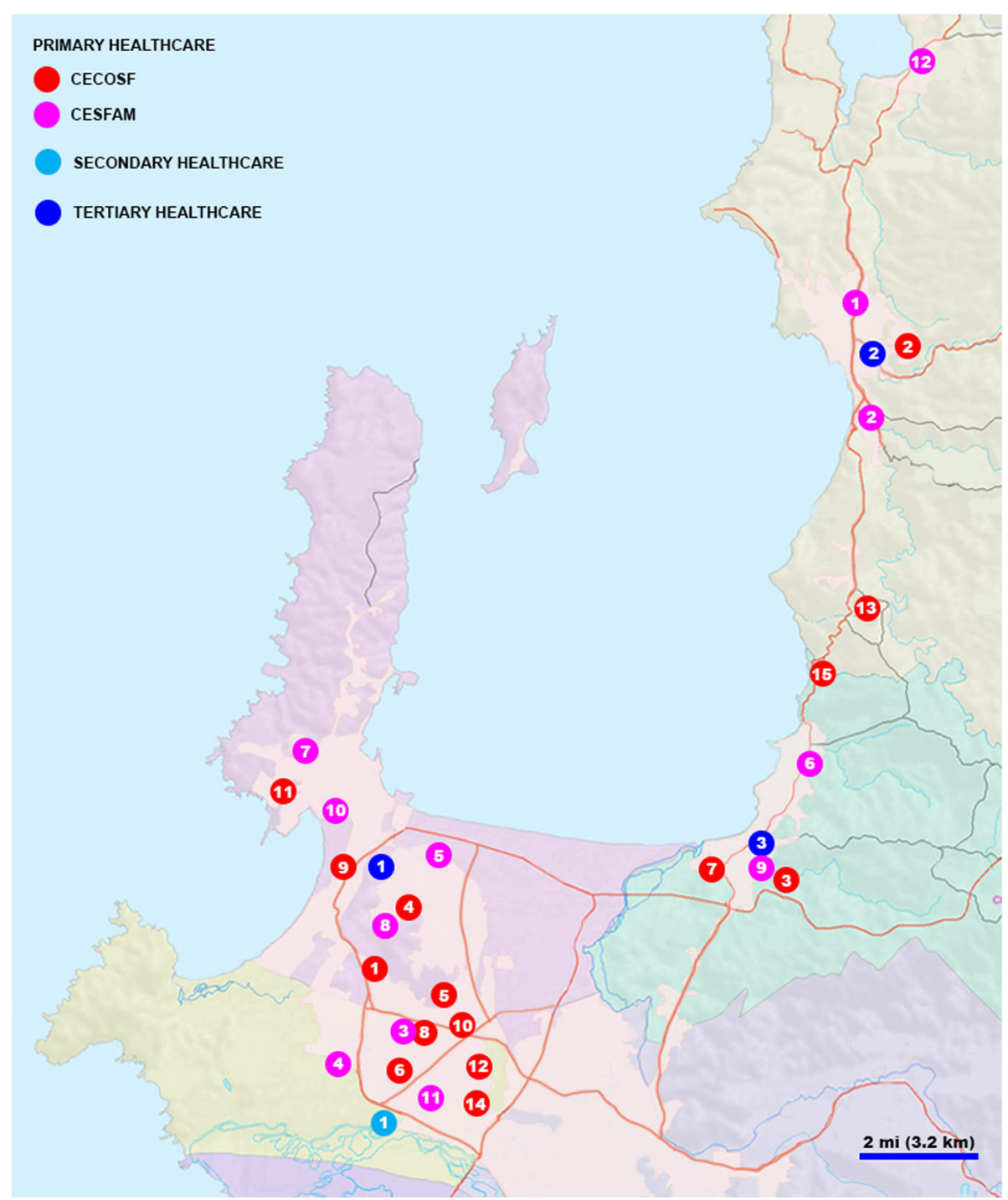

Fig. 2 Geographical location of primary, secondary and tertiary healthcare facilities referring patients to the Neurology clinic at HHT 
support the success of the Teleneurology Program at HHT in providing highly-accessible and satisfactory healthcare. Adoption of this type of programs by the Chilean Public Healthcare System would allow a consistent contribution to the country-wide decrease in both the number of patients waiting for a first appointment and the waiting time. This would entail: $i$ ) continuing medical education for all health personnel at different levels of care, ii) creation of protocols for resolving the most common pathologies, with appropriate reference and counter-referral criteria, iii) a good residence on-call schedule allowing the admittance of in-patients with severity criteria outside the scope of a Teleneurology protocol, iv) a high-quality neurological in-patient admittance service, allowing for study and therapy with clear standards and criteria, and $v$ ) efficient hierarchy of in situ care, including the support by general practitioners to unburden specialist with low complexity follow-ups, such as prescription refills. Currently, the Neurology unit at the HHT is extensively working in quality of care assurance, continuing education and looking forward to broadening their coverage of the neurological patient population in the region, due to an absence of patient in the waiting for a first consultation.

\section{Conclusions}

Here we concluded that the HHT Teleneurology Program had a significant impact in reducing both outcomes: the number of patients waiting for an adult neurology consultation and their waiting times. We propose to continue this experience in other Chilean health centers, and to focus our efforts in the waiting list of control patients.

\section{Supplementary information}

Supplementary information accompanies this paper at https://doi.org/10. 1186/s12911-020-1034-2.

Additional file 1. Data based used in the present study.

\section{Abbreviations}

SST: Health Service of Talcahuano of the Ministry of Health; HHT: Hospital las Higueras of Talcahuano; NU: Neurology Unit

\section{Acknowledgements}

We thank all the staff personnel of the Neurology Unit at the HHT, for their invaluable contributions to this work.

\section{Authors' contributions}

FC: Study conception and design, patient's medical attention, and manuscript elaboration. PAS: Manuscript elaboration and English editing. JPH: Statistical analysis. LP: Patient's medical attention. MM: Patient's medical attention. JG: Patient's medical attention. GV: Supervision of Teleprocesses for the Teleneurology program at HHT. CA: Coordination of researchers, statistical analysis, manuscript elaboration and English editing. All authors read and approved the final manuscript.

Funding

Not applicable.

\section{Availability of data and materials}

The dataset supporting the conclusions of this article is included within the article and its additional file.

\section{Ethics approval and consent to participate}

The research protocol was approved by the Scientific Ethics Committee of the SST of the Ministry of Health. As a retrospective random study, the patient's consent of publication is not applicable nor required by the Scientific Ethics Committee of the SST of the Ministry of Health.

\section{Consent for publication}

Not applicable.

\section{Competing interests}

I declare that me (Dr. Freddy Constanzo) and all the authors included in this manuscript have no conflict of interest.

\section{Author details}

${ }^{1}$ Neurology Unit, Hospital Las Higueras, Alto Horno 777, Talcahuano, Chile. ${ }^{2}$ Medical Program in Adult Neurology, School of Medicine, Universidad Católica de la Santísima Concepción, Concepción, Chile. ${ }^{3}$ Department of Science, School of Medicine and Science, Universidad San Sebastián, Concepción, Chile. ${ }^{4}$ Department of Statistics, School of Sciences, Universidad del Bío-Bío, Concepción, Chile. ${ }^{5}$ Unit of Teleprocesses, Hospital Las Higueras, Talcahuano, Chile. ${ }^{6}$ Department of Basic Sciences, School of Medicine, Universidad Católica de la Santísima Concepción, Concepción, Chile.

Received: 22 October 2019 Accepted: 24 January 2020

Published online: 05 February 2020

\section{References}

1. Sistema Estadístico Nacional. Instituto Nacional de Estadísticas. 2019. Available from: https://www.ine.cl/. Cited 6 Oct 2019

2. Guillou M, Carabantes CJ, Bustos FV. Availability of physicians and specialists in Chile. Rev Med Chil. 2011;139(5):559-70 Available from: http://www.ncbi. nlm.nih.gov/pubmed/22051705. Cited 5 July 2017.

3. de Salud M. Informe sobre Brechas de Personal de Salud por Servicio de Salud. 2018. Available from: https:/www.minsal.cl/wp-content/uploads/2015/08/ Informe-Brechas-RHS-en-Sector-Público_Abril2017.pdf. Cited 7 Mar 2019.

4. FONASA. Bases de datos, Informes, Estudios y Documentos. 2017. Available from: https://www.fonasa.cl/sites/fonasa/institucional/archivos\#documentosestadisticos-institucionales. Cited 9 Oct 2019.

5. Ministerio de Salud de C. GLOSA 06 Ley de Presupuesto 2019. 2019; Available from: https:/www.minsal.cl/wp-content/uploads/2019/08/Ord.-33 79-Glosa-06-LE-GES-y-No-GES-Jun-2019.pdf. Cited 6 Oct 2019.

6. Rienzo A, Galindo C. Telemedicine services in the chilean public sector; a first quantitative study. In: 2015 CHILEAN Conference on Electrical, Electronics Engineering, Information and Communication Technologies (CHILECON). Santiago: IEEE; 2015. p. 215-8. Available from: http://ieeexplore. ieee.org/document/7400378/. Cited 28 Sept 2019.

7. Ossandón D, Zanolli M, Stevenson R, Agurto R, Ortiz P, Dotan G. A national telemedicine network for retinopathy of prematurity screening. J Am Assoc Pediatr Ophthalmol Strabismus. 2018;22(2):124-7 Available from: https:/ www.sciencedirect.com/science/article/pii/S1091853117308017?via\%3Dihub. Cited 28 Sept 2019

8. Escobar E, Akel C. Telemedicine: its importance in cardiology practice. Experience in Chile. Cardiovasc Innov Appl. 2017;2(3):325-31 Available from: https:/www.ingentaconnect.com/content/10.15212/CVIA.2016.0043. Cited 28 Sept 2019.

9. Fuenzalida Cruz H, Jimeno Ortega I, Toso Díaz de la Vega S, Sepúlveda Muñoz A, Loubies Muñoz R. Teledermatología: impacto de una herramienta de gestión informática para zonas remotas de Chile. Piel. 2017;32(5):257-62 Available from: https://www.sciencedirect.com/science/article/pii/S0213 925116303495?via\%3Dihub. Cited 28 Sept 2019

10. Prada C, Izquierdo N, Traipe R, Figueroa C. Results of a new telemedicine strategy in traumatology and orthopedics. Telemed eHealth. 2019:tmj.2019.0090 Available from: http://www.ncbi.nlm.nih.gov/ pubmed/31287786. Cited 6 Oct 2019.

11. Kane CK, Gillis K. The use of telemedicine by physicians: still the exception rather than the rule. Health Aff. 2018;37(12):1923-30 Available from: http:// www.healthaffairs.org/doi/10.1377/hlthaff.2018.05077. Cited 28 Sept 2019. 
12. LeRouge CM, Gupta M, Corpart G, Arrieta A. Health system approaches are needed to expand telemedicine use across nine Latin American nations. Health Aff. 2019;38(2):212-21 Available from: http://www.healthaffairs.org/ doi/10.1377/hlthaff.2018.05274. Cited 28 Sept 2019.

13. Unidad de Informacion en Salud SDST. Poblacion Asignada (INE) 2019 Servicio de Salud Talcahuano. 2019; Available from: http://sstalcahuano.cl/ wp-content/uploads/2019/09/Poblacion-INE-2019.pdf. Cited 6 Oct 2019.

14. Bossert TJ. Decision space and capacities in the decentralization of health services in Fiji: comment on "decentralisation of health services in Fiji: a decision space analysis". Int J Heal policy Manag. 2016;5(7):443-4 Available from: http://www.ncbi.n/m.nih.gov/pubmed/27694673. Cited 5 July 2017

15. Constanzo F, Aracena-Sherck P, Hidalgo JP, Muñoz M, Vergara G, Alvarado C. Validation of a patient satisfaction survey of the Teleneurology program in Chile. BMC Res Notes. 2019;12(1):359 Available from: https://bmcresnotes. biomedcentral.com/articles/10.1186/s13104-019-4358-1. Cited 23 July 2019.

16. Mutgi SA, Zha AM, Behrouz R. Emerging subspecialties in neurology: telestroke and teleneurology. Neurology. 2015;84(22):e191-3 Available from: http://www.ncbi.nlm.nih.gov/pubmed/26033342. Cited 5 July 2017.

17. Timpano F, Pirrotta F, Bonanno L, Marino S, Marra A, Bramanti $P$, et al. Videoconference-based mini mental state examination: a validation study. Telemed e-Health. 2013;19(12):931-7 Available from: http://www.ncbi.nlm. nih.gov/pubmed/24073900. Cited 5 July 2017.

18. Davis LE, Coleman J, Harnar J, King MK. Teleneurology: successful delivery of chronic neurologic care to 354 patients living remotely in a rural state. Telemed J E Health. 2014;20(5):473-7 Available from: https://www. liebertpub.com/doi/10.1089/tmj.2013.0217. Cited 26 Sept 2019.

19. Mullen-Fortino M, Rising KL, Duckworth J, Gwynn V, Sites FD, Hollander JE. Presurgical assessment using telemedicine technology: impact on efficiency, effectiveness, and patient experience of care. Telemed e-Health. 2019;25(2): 137-42 Available from: http://www.ncbi.nlm.nih.gov/pubmed/30048210. Cited 26 Sept 2019.

20. Salud. M de. Gobierno de elite GLOSA 06 LISTA DE ESPERA NO GES Y GARA NTÍAS DE OPORTUNIDAD GES RETRASADAS. SEPTIEMBRE 2018. Santiago; 2018. Available from: https://www.minsal.cl/wp-content/uploads/2018/05/ Glosa-6-Septiembre-2018.pdf. Cited 7 Mar 2019.

21. Lertmaharit S, Kamol-Ratankul P, Sawert H, Jittimanee S, Wangmanee S. Factors associated with compliance among tuberculosis patients in Thailand. J Med Assoc Thai. 2005;88(Suppl 4):S149-56 Available from: http:// www.ncbi.nlm.nih.gov/pubmed/16623020. Cited 6 Oct 2019.

22. Lester J, Weinstock MA. Teletriage for provision of dermatologic care. J Cutan Med Surg. 2014;18(3):170-3 Available from: http://journals.sagepub. com/doi/10.2310/7750.2013.13086. Cited 6 Oct 2019

23. Borooah S, Grant B, Blaikie A, Styles C, Sutherland S, Forrest G, et al. Using electronic referral with digital imaging between primary and secondary ophthalmic services: a long term prospective analysis of regional service redesign. Eye (Lond). 2013;27(3):392-7 Available from: http://www.ncbi.nlm. nih.gov/pubmed/23258310. Cited 6 Oct 2019.

24. Dorsey ER, Glidden AM, Holloway MR, Birbeck GL, Schwamm LH. Teleneurology and mobile technologies: the future of neurological care. Nat Rev Neurol. 2018;14(5):285-97 Available from: http://www.nature.com/ doifinder/10.1038/nrneurol.2018.31. Cited 20 Dec 2018.

25. Van Dyk L. A review of telehealth service implementation frameworks. Int Environ Res Public Health. 2014;11(2):1279-98 Available from: http://www. ncbi.nlm.nih.gov/pubmed/24464237. Cited 9 Oct 2019.

26. Ford JA, Pereira A. Does teledermatology reduces secondary care referrals and is it acceptable to patients and doctors?: a service evaluation. J Eval Clin Pract. 2015;21(4):710-6 Available from: http://www.ncbi.nlm.nih.gov/ pubmed/25903046. Cited 6 Oct 2019

27. Ganapathy K. Telemedicine and neurosciences. Neurol India. 2018;66(3): 642 Available from: http://www.ncbi.nlm.nih.gov/pubmed/29766913. Cited 6 Oct 2019

28. Legris N, Hervieu-Bègue M, Daubail B, Daumas A, Delpont B, Osseby G-V, et al. Telemedicine for the acute management of stroke in Burgundy, France: an evaluation of effectiveness and safety. Eur J Neurol. 2016;23(9):1433-40 Available from: http://doi.wiley.com/10.1111/ene.13054. Cited 6 Oct 2019.

29. Latifi R, Dasho E, Shatri Z, Tilley E, Osmani KL, Doarn CR, et al. Telemedicine as an innovative model for rebuilding medical systems in developing countries through multipartnership collaboration: the case of Albania. Telemed e-Health. 2015;21(6):503-9 Available from: https://www.liebertpub. com/doi/10.1089/tmj.2014.0138. Cited 6 Oct 2019
30. O'Shea J, Berger R, Samra C, Van Durme D. Telemedicine in education: bridging the gap. Educ Heal. 2015;28(1):64 Available from: http://www. educationforhealth.net/text.asp?2015/28/1/64/161897. Cited 6 Oct 2019.

31. Walker C, Echternacht $H$, Brophy PD. Model for medical student introductory telemedicine education. Telemed e-Health. 2019;25(8):717-23 Available from: https://www.liebertpub.com/doi/10.1089/tmj.2018.0140. Cited 6 Oct 2019.

\section{Publisher's Note}

Springer Nature remains neutral with regard to jurisdictional claims in published maps and institutional affiliations.

\section{Ready to submit your research? Choose BMC and benefit from:}

- fast, convenient online submission

- thorough peer review by experienced researchers in your field

- rapid publication on acceptance

- support for research data, including large and complex data types

- gold Open Access which fosters wider collaboration and increased citations

- maximum visibility for your research: over $100 \mathrm{M}$ website views per year

At BMC, research is always in progress.

Learn more biomedcentral.com/submissions 